Original article

\title{
Original hardware-software method for treatment of infected superficial wounds in a liquid environment
}

\author{
Alexandr A. Basov ${ }^{1,2}$, Vadim V. Malyshko ${ }^{1,3}$, Anna A. Elkina ${ }^{2,3}$, Arkadii V. Moiseev ${ }^{4}$, Stepan S. Dzhimak ${ }^{2,3}$ \\ ${ }^{1}$ Kuban State Medical University, Krasnodar, Russia \\ ${ }^{2}$ Kuban State University, Krasnodar, Russia \\ ${ }^{3}$ Southern Scientific Centre of Russian Academy of Sciences, Rostov-on-Don, Russia \\ ${ }^{4}$ Kuban State Agrarian University, Krasnodar, Russia
}

Received 12 August 2018, Revised 13 March 2019, Accepted 11 September 2019

(C) 2018, Basov A.A., Malyshko V.V., Elkina A.A., Moiseev A.V., Dzhimak S.S.

(C) 2018, Russian Open Medical Journal

Abstract: Aim - development of a hardware-software system allowing to treat infected superficial wounds in a liquid environment, designed to provide continuous flow of various irrigation solutions (depending on the wound healing stage) under airtight and waterresistant film tightly fixed over the wound.

Methods - in this experiment wound irrigation with antiseptic, oxidizing antiseptic and osmotically active agents with subsequent exposure and drainage was performed using the novel device. Efficacy of the proposed hardware-software system was evaluated by comparing it with standard wound dressings by planimetry and wound biopsy results.

Results - according to study results the novel device reduces the time of wound healing by $26.1 \%$, while the time to wound proliferation is 1.7 times shorter when compared with standard wound dressings.

Conclusion - the proposed method stimulates wound repair and limits purulent inflammation in infected wounds. Using the novel method of superficial wound management helps to prevent the development of re-infection and suppuration.

Keywords: wound, dressing, hardware device, antiseptic, software system.

Cite as Basov AA, Malyshko VV, Elkina AA, Moiseev AV, Dzhimak SS. Original hardware-software method for treatment of infected superficial wounds in a liquid environment. Russian Open Medical Journal 2019; 8: e0409.

Correspondence to Anna A. Elkina. Address: Kuban State University, Stavropolskaya street 149, Krasnodar, Russia. Phone: +79180688381. E-mail: 013194@mail.ru.

\section{Introduction}

To this moment many different methods for treatment of infected wounds have been developed and tested (Patent № WO2005105175, 26.04.2005), but development and modernization of techniques for surgical management of inflammatory conditions in order to improve its efficacy is still relevant [1-6]. Existing approaches to surgical treatment often involve placement of various opaque materials directly onto the wound [7-10], which limits the dynamic control of wound healing during the treatment [11] and increases the risk of delayed diagnosis that may lead to an increased rate of disabling complications of the wound healing process [12-14]. In addition, rapid contamination of porous materials (e.g. dressing or fluid transfer components) with rejected necrotic tissue fragments and sequestrations during the exudation phase [15-18], which leads to the formation of bacterial biofilms on the surface of these materials [19-22], can be an additional source of wound infection [23].

Moreover, the use of materials of natural origin for wounds treatment (Russian Federation Patent № 2429887, 27.09.2011 [24, 25]) may lead to fiber depolymerization (e.g. when using viscose
[26]), which often occurs as a result of specific bacterial or fungal flora [26], including Pseudomonas bacteria [27], yeasts and conditionally pathogenic micromycetes such as Alternaria, Trichoderma, Chaetomium, Aspergillus, Penicillium, Cladosporium [28], appearing in the wound environment. Also, the destruction of viscose fibers may increase in wet conditions created during treatment and the resulting swelling leads to a decrease in fiber strength by $50 \%$ [29]. Some agents (such as sodium tetraborate and chloramine [29]) which create an alkaline environment in the wound (e.g., $6 \%$ solution of $\mathrm{NaOH}$ increases the fiber solubility by $22 \%$ [29]), increase the risk of wound contamination by resulting debris [30], as well as the risk of suppuration due to reinfection $[27,31]$.

The purpose of this study was to evaluate the efficacy of the developed method for treatment of infected superficial wounds in a liquid environment using a special hardware-software system, which allows to remove rejected necrotic tissue fragments and sequestrations directly from the wound surface in the automatic mode, reducing the probability of bacterial biofilm formation on device components, and to monitor wound condition during the whole treatment period. 


\section{Material and Methods}

Method of treating infected wounds using a hardwaresoftware complex

The new method of experimental treatment for infected wounds includes its preliminary surgical debridement with subsequent sealed fixation of airtight and water-resistant transparent film over the wound [32]. Depending on the phase of the wound process a continuous flow of various solutions was maintained: antiseptic, antiseptic-oxidant (sodium hypochlorite) and osmotically active agent $-1.0-2.5 \%$ sodium chloride [33]. Sequential exposure to these solutions for a certain period of time was followed by active drainage using a peristaltic pump. The replacement of airtight and water-resistant film should be done every 3 days. Equipment necessary for this hardware-softwarebased method of treatment for infected wounds is presented in Figures 1-3.

It also enables the possibility of setting exposure time for each solution and controlling its subsequent active drainage.

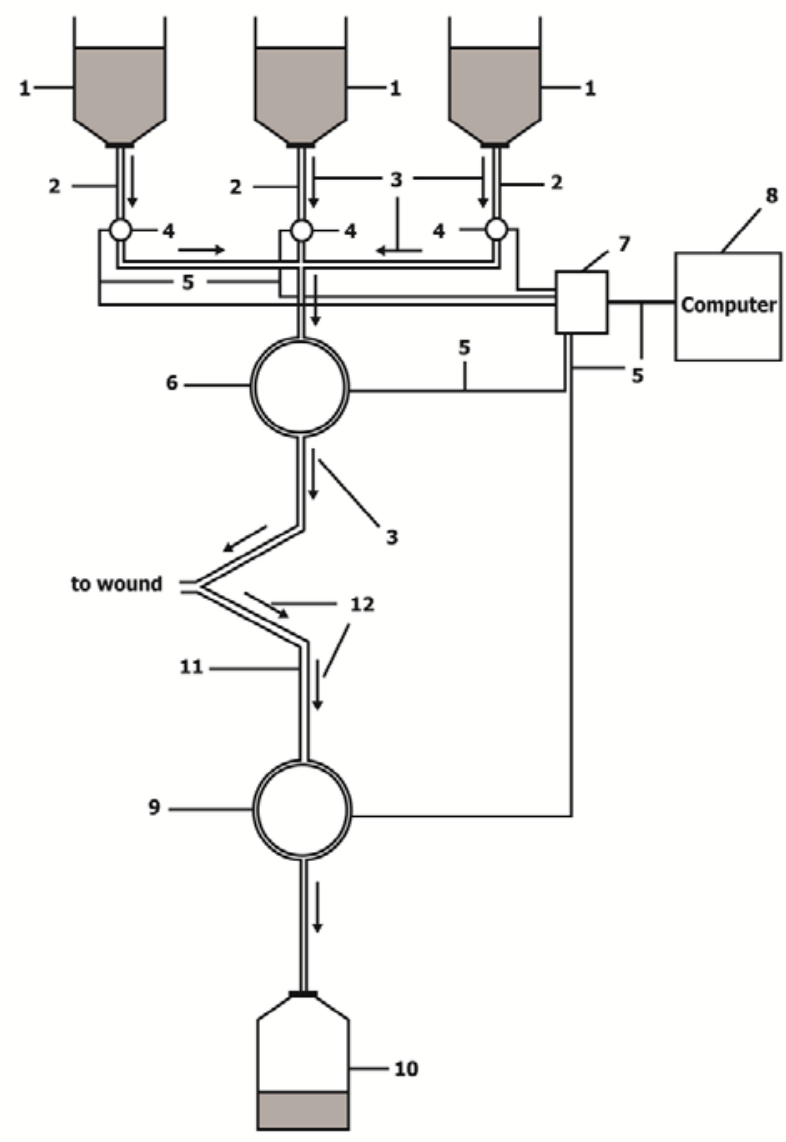

Figure 1. Device for local treatment and visual control of the surface of infected wounds (general scheme). 1 - container with irrigation solutions; 2 - irrigation tube; 3 - direction of solution flow; 4 - electromagnetic valves; 5 - connecting cables; $\mathbf{6}$ - influx peristaltic pump for drainage of irrigation solution; 7 - microprocessor; 8 - computer; 9 - source of negative pressure: 10 - container for waste collection; 11 - drainage tube; 12 - direction of drainage flow.

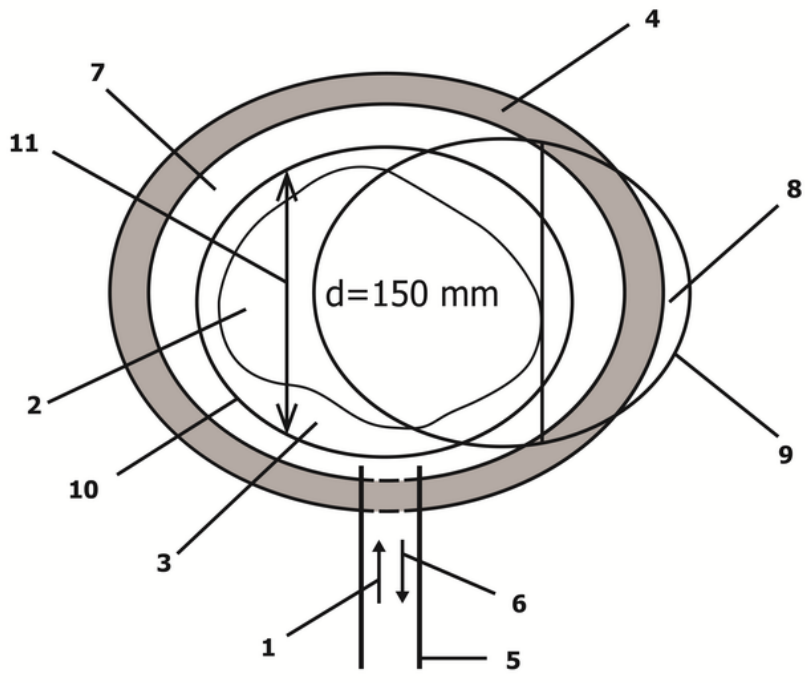

to the hardware

Figure 2. Removable round-shaped cap for local treatment of infected superficial wounds (wound area, view from the top). 1 - direction of solution flow; 2 - wound bottom; 3 - intact skin around the wound; 4 adhesive agent of the base film; 5 - irrigation and drainage tubes; 6 direction of drainage flow; 7 - elastic film; 8 - removable round-shaped cap made from a transparent material with a diameter of $150 \mathrm{~mm}, 9$ elastic flexible seal-rings; 10 - groove-ring seal, 11 - window.

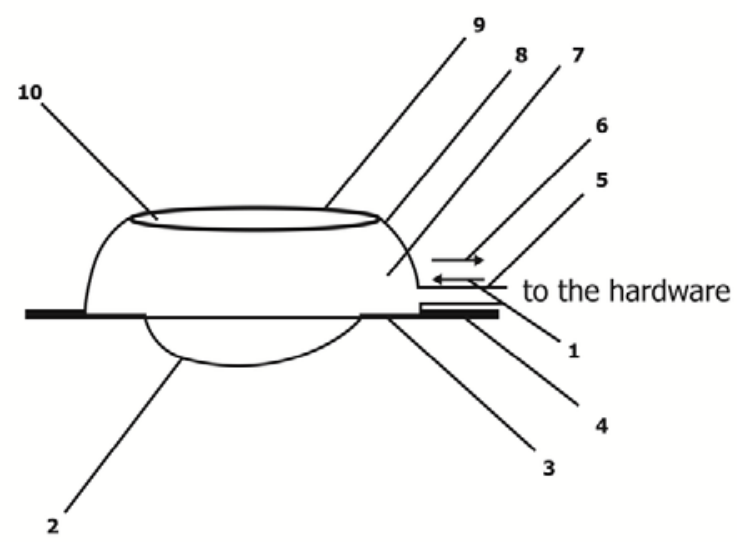

Figure 3. Removable round-shaped cap for local treatment of surface purulent wound (wound area, side view). 1 - direction of solution flow; 2 - wound bottom; 3 - intact skin around the wound; 4 - adhesive agent of the base film; 5 - irrigation and drainage tube; 6 - direction of drainage flow; 7 - cavity formed by elastic film, bottom and walls of the wound; 8 - elastic film; 9 - elastic flexible seal-rings; 10 - removable roundshaped cap made from a transparent material with a diameter of $\mathbf{1 5 0}$ $\mathrm{mm}$.

\section{Developed hardware-software complex}

The developed device (Russian Federation patent № 163627, 27.07.2016) includes:

1) source of negative pressure connected to waste container via system of tubes,

2) influx peristaltic pump connected with containers for pharmaceutical solutions which regulate volume of 
fluids and provide the flow of solution into the wound through the system of electromagnetic valves,

3) microprocessor connected with the electromagnetic valves, influx pump and source of negative pressure (outflow pump) by electrical wires,

4) elastic film attached to the base of the wound with an adhesive,

5) removable round-shaped cap made from a transparent material with a diameter of $150 \mathrm{~mm}$ (Figures 2 and 3) attached to the film by elastic flexible seal-rings consisting of two parts,

6) one part of elastic flexible seal-rings is soldered to a cap and has an edge, and the other part is soldered with the film and has a slot.

Software (Russian Federation certificate of state registration of computer program № 2015615207, 13.05.2015) for the described device is used to control the influx pump, outflow pump and three electromagnetic valves. In the "pause" mode the software provides the conditions for time control of exposure to pharmaceutical solutions in a cavity formed between the wound and transparent airtight water-resistant film. The program also creates a log file that records each action at the moment of it execution. Thus, it is easily possible to trace any activities which were carried out, facilitating the quality control for implementation of medical treatment.

\section{Characteristics of the laboratory animals}

Evaluation of efficacy of the developed hardware-software treatment method for infected wounds was performed on experimental animals - rabbits (after approval by the Kuban State Medical University Ethical Committee, registration number 45, 25.10.2016, Krasnodar, Russian Federation): male "Grey Giant» rabbits weighing 2.5-2.7 kg, which were kept in standard conditions in Kuban State Medical University vivarium (temperature $20 \pm 3^{\circ} \mathrm{C}$, humidity $48 \pm 2 \%$, coverage mode day/night: from 6.00 to 18.00 / from 18.00 to 6.00), received «K-92-1» feed for adult rabbits (LLC «FIDLAYF», Russia), containing the following ingredients: ground oats and wheat $-30 \%$, ground barley and corn $-40 \%$, wheat bran $-12 \%$, alfalfa $-5 \%$, oilcake, sunflower meal $12 \%$, chalk $-0.5 \%$, salt $-0.5 \%$.

\section{Experiment design}

Animals were divided into comparison Group $1(n=10)$ and experimental Group $2(n=10)$. In comparison group wounds were treated with standard method (under the dressing with ointment) with daily wound care with $0.02 \%$ aqueous solution of chlorhexidine and "Laevomecolum» ointment application (this drug is based on polyethylene glycol and contains antibiotic chloramphenicol and immune stimulant agent - methyluracilum).

In the experimental group the developed hardware-software method for infected wounds was used. An infected wound model was made by the abscess formation method (Russian Federation patent № 2455703), which was performed by introducing a gauze ball soaked overnight with a culture of Staphylococcus aureus pathogenic strain in concentration about $10^{8} \mathrm{CFU} / \mathrm{ml}$ into the wound. The abscess formation was done according to the procedure described below.
We used combination of $10 \mathrm{mg} / \mathrm{kg}$ "Zoletil 100" (Virbac, France) and $0.1 \mathrm{ml} / \mathrm{kg} 2 \%$ "Xylazine" (Interchemie Werken "de Adelaar" BV, Netherlands) for analgesia. After treating the intervention area on the rabbit's back with an alcohol solution (96\%) a skin incision was made, subcutaneous tissue and fascia propria of musculus erector spinae were divided. The gauze ball soaked in 1-day culture of Staphylococcus aureus pathogenic strain in concentration of $10^{8} \mathrm{CFU} / \mathrm{ml}$ was implanted into the wound. After that the wound was closed by stitching up the skin edges with a purse-string suture. One hundred twenty hours after the infected gauze ball implantation the abscess of soft tissue was formed in the purulent wound. That was achieved by removing the infected gauze ball out of the wound and restoration of abscess cavity. This method provides the biphasic experimental model of soft tissue acute inflammation with adjustable duration and severity.

In the first pyonecrotic phase of wound healing process an antiseptic $(0.05 \%$ aqueous solution of chlorhexidine at $20 \mathrm{ml} / \mathrm{min}$ ) was instilled into cavity between the wound and the airtight water-resistant transparent film for a period of 10 minutes which was controlled by the developed software. After that the active drainage of the wound contents was conducted by the peristaltic pump from the cavity limited by a transparent elastic film. Next, the antiseptic-oxidant $(800 \mathrm{mg} / \mathrm{ml}$ sodium hypochlorite at 20 $\mathrm{ml} / \mathrm{min}$ ) solution was instilled into wound cavity for 1 minute, and the duration of exposure was 15 minutes in «pause» mode. After that active drainage of contents from the cavity limited by a transparent elastic film was performed using peristaltitc pump. Afterwards an instillation of osmotically active agent ( $2.5 \%$ sodium chloride, $20 \mathrm{ml} / \mathrm{min}$ ) was conducted for 4 minutes. The duration of osmotically active agent exposure was 15 minutes in the "pause" mode.

The influx-drainage cycle of pharmaceutical solutions described above was carried out throughout the first phase of wound healing process. In the second (proliferative) phase of wound healing process sodium chloride irrigation duration was reduced to 2 minutes and the sodium chloride concentration was reduced to $1.5 \%$. In the third phase of wound healing process antiseptic administration was reduced to 5 minutes, antiseptic oxidant (sodium hypochlorite) was not instilled, and the concentration of sodium chloride was reduced to $1 \%$. This influxdrainage cycle of pharmaceutical solutions continued until granulations appeared in the wound and epithelialization began, and then the water-resistant transparent film was removed.

\section{Evaluation of wound healing parameters}

During the wound healing the following parameters were evaluated: wound cleansing (transition to second phase), frequency of re-infection (different flora in the wound), frequency of continuing purulence after suturing. The study of cellular composition of the wound surface was performed by biopsy [34] immediately after the wound formation and on 3, 5, 7, 11 and 14 days from the date of abscess opening and the start of using hardware-software method of treatment. The surface biopsy consisted of slightly scraping the surface layer of the wound with a special handle of surgical spatula or scalpel. To evaluate the samples provided by superficial biopsy Romanovsky-Giemsa staining was done, followed by calculation of neutrophil and fibroblast percentage. The advantage of this method includes the possibility to obtain cellular elements, superficial (granular-fibrous) 
wound layer and layer of newly formed cells, which provides more data on the wound regeneration.

Wound area was measured (Russian Federation patent № 2301626, 27.06.2007) immediately after wound formation (start point) and on 3, 5, 7, 11 and 14 days after the start of using the hardware-software treatment. This method of measuring wound surface area allows to perform evaluation without direct contact and with high accuracy and speed, because of the following steps:

a) digital photography of the wound with juxtaposed standard "№1" (we used 10×10 mm piece of white paper),

b) transfer of digital image to the computer,

c) calculation of the wound area using the following formula:

$\mathrm{S}_{\text {wound }}=\left(\mathrm{N}_{\text {defect }} / \mathrm{N}_{\text {standard }}\right) \times \mathrm{S}_{\text {standard, }}$

$\mathrm{S}_{\text {wound }}$ - wound area (skin defect) in $\mathrm{mm}^{2} ; \mathrm{S}_{\text {standard }}$ - standard area in $\mathrm{mm}^{2} ; \mathrm{N}_{\text {defect }}$ - the number of wound pixels on the digital image; $\mathrm{N}_{\text {standard }}$ - number of pixels covering the standard on digital image.

After that a series of digital photographs of the skin defect, as described above, was done at specific intervals, and dynamic parameters of the skin defect area such as a ratio of the difference between the previous and current values of the wound area were calculated. The dynamics of the speed of wound healing were calculated using the following formula:

$$
\left.V=\left(\left(S_{d[a]}-S_{d[b}\right]\right) \times 100\right) /\left(S_{d[b]} \times(b-a)\right),
$$

$V$ - speed of wound healing for «a-b» interval in \% per day; $\mathrm{S}_{\mathrm{d}[\mathrm{a}]}$ - wound area (skin defect) measured on previous day (taken as $100 \%$ ) in $\mathrm{mm}^{2} ; \mathrm{S}_{\mathrm{d}[\mathrm{b}]}$ - wound area (skin defect) measured on following day (b) in $\mathrm{mm}^{2}$; a - number of a previous day since the wound formation; $b$ - number of a following day since the date of wound formation; 100 - percentage.

\section{Statistical analysis}

Statistical analysis was performed using specialized software. Results were presented as arithmetic mean (M) and standard deviation $(\sigma)$. Statistical significance of findings was evaluated using non-parametric U-test (Mann-Whitney test, difference was considered to be statistically significant at $p<0.05$ ).

\section{Results}

It was found (Table 1) that transition to second phase of wound healing process (proliferative phase) in animals from Group 2 was 1.7 times shorter when compared to Group 1. Also, in rabbits from Group 2 total healing time of experimental wound was shorter by $26.1 \%$ when compared to Group 1 . In Group 1 following complications were observed during treatment of infected wounds: 1 case of continuing purulence after wound closure and 2 cases of reinfection (Table 1). The causative agent of reinfection was Escherichia coli. The study of a wound healing process revealed that wound area diminished faster beginning from the third day in animals from Group 2 versus Group 1 (Table 2). Thus on $11^{\text {th }}$ day the wound area in animals from Group 2 was 7.5 times less than in rabbits from Group 1. This indicates substantially higher efficacy of the proposed method of superficial wounds treatment. In addition, from $3^{\mathrm{d}}$ to $5^{\text {th }}$ day the wound area decreased by $487 \mathrm{~mm}^{2}$ on average in Group 1, whereas in Group 2 it decreased by $61.2 \%$ (785 $\mathrm{mm}^{2}$ on average), and this difference was statistically significant.
To assess efficacy of the wound treatment the reduction of its area per one day was calculated for both groups (Table 3). It was found that in Group 1 the lowest healing rate was registered in the period beginning from treatment start until day 3 . Then we observed an increase of this parameter due to contraction and epithelization of the wound. In days 11 to 14 the highest increase in the rate of wound healing was observed due to the achievement of maximal local regenerative potential. Also it is noted that in Group 1 on $14^{\text {th }}$ day from the treatment start in 4 of 10 cases complete healing of experimental wounds was observed. At the same time a significant difference in the rate of wound healing between Groups 1 and 2 was shown (until days 7-11), but in days 3-5 and days 5-7 the rate of wound healing in Group 2 was almost 2 times higher than the rate of wound healing in Group 1 (Table 3).

The minimal rate of wound healing was observed during the period from beginning of treatment to day 3 in Group 2, but even in this period the above-mentioned variable was significantly higher by $73.4 \%$ than in Group 1. Maximal reduction of wound area per day in Group 2 was observed during days 5 to $7\left(497.0 \mathrm{~mm}^{2} /\right.$ day). In Group 1 maximal reduction of wound area per day was observed during days 7 to 11 (413.8 $\mathrm{mm}^{2} /$ day). So the highest activity of reparative processes in the Group 1 was observed later (by 2-4 days) than in Group 2, where patients were treated with proposed hardwaresoftware method. The maximal healing rate per day was higher by $20.1 \%$ in Group 2 in comparison with Group 1.

In the periods from 7 to 11 days and from 11 to 14 days the decrease of wound area per day was higher in group 1 than in Group 2, and this was associated with the delay of regenerative processes in Group 1 (Table 3). This is confirmed by the differences in mean values of wound area (Table 2): on day 7 the average wound area in Group 1 was 57.2\% larger than in Group 2. It should be noted that on day 11 wound completely healed in 6 rabbits from Group 2, and on day 14 healing process was complete in other two rabbits (eight out of ten total) in this group.

Surface biopsy performed during the experimental period in both treatment groups revealed the decreased number of neutrophils and increased growth of the fibroblasts, with this process being most rapid in Group 2 (Table 4).

After the beginning of treatment (day 0 ) neutrophil and fibroblast count in cytograms did not show significant differences between Groups 1 and 2. The cellular population was represented mainly by neutrophils, but fibroblasts were also observed rarely.

During the period between days 3 and 7 there was a significant difference between the treatment groups in number of neutrophils and number of fibroblasts. A gradual decrease in number of neutrophils accompanied by increased fibroblasts number was observed, and this process was faster in Group 2. Moreover, on day 7 the number of fibroblasts in Group 2 was 2.1 times higher than in Group 1, while the number of neutrophils in Group 2 was $36.1 \%$ less than in Group 1.

Table 1. Parameters of wound healing process in the experimental treatment of infected superficial wounds in a liquid environment

\begin{tabular}{ccccc}
\multicolumn{6}{c}{$\begin{array}{c}\text { Time of } \\
\text { wound } \\
\text { cleansing, } \\
\text { day }(M \pm \sigma)\end{array}$} & $\begin{array}{c}\text { Time of } \\
\text { wound } \\
\text { healing, day } \\
(M \pm \sigma)\end{array}$ & $\begin{array}{c}\text { Suppuration } \\
\text { after } \\
\text { suturing, } \%\end{array}$ & Reinfection, \% \\
& $8.1 \pm 0.9$ & $13.9 \pm 1.4$ & & \\
\hline Group 1 & $4.7 \pm 0.8^{*}$ & $10.7 \pm 2.7^{*}$ & 0 & 20 \\
Group 2 & & 0 & 0 \\
\hline
\end{tabular}

* $-p<0.05$ as compared with Group 1. 
Table 2. Dynamics of wound area during treatment

\begin{tabular}{|c|c|c|c|c|c|c|}
\hline \multirow[t]{2}{*}{ Index } & \multicolumn{6}{|c|}{ Day of wound treatment, $M \pm \Sigma[M I N-M A X]$} \\
\hline & Start point $(0)(n=10)$ & $3(n=10)$ & $5(n=10)$ & $7(n=10)$ & $11(\mathrm{n}=10)$ & $14(n=10)$ \\
\hline Wound area, $\mathrm{mm}^{2}$ & $4008 \pm 18$ & $3636 \pm 75$ & $3149 \pm 56$ & $2498 \pm 29$ & $843 \pm 49$ & $92 \pm 81$ \\
\hline (Group 1) & {$[3984-4041]$} & {$[3529-3712]$} & {$[3039-3216]$} & {$[2465-2548]$} & {$[782-931]$} & {$[0-182]$} \\
\hline Wound area, $\mathrm{mm}^{2}$ & $4013 \pm 32$ & $3367 \pm 64^{*}$ & $2582 \pm 42 *$ & $1589 \pm 35^{*}$ & $112 \pm 147^{*}$ & $9 \pm 20^{*}$ \\
\hline (Group 2) & {$[3975-4068]$} & {$[3287-3488]$} & {$[2495-2631]$} & {$[1532-1653]$} & {$[0-326]$} & {$[0-51]$} \\
\hline
\end{tabular}

* $-\mathrm{p}<0.05$ as compared with Group 1.

Table 3. Dynamics of wound area depending on treatment method

\begin{tabular}{|c|c|c|c|c|c|}
\hline \multirow[t]{2}{*}{ Index } & \multicolumn{5}{|c|}{ Treatment period, days } \\
\hline & Start point $(0)-3$ & $3-5$ & $5-7$ & $7-11$ & $11-14$ \\
\hline Rate of healing, \% per day (Group 1), & $3.09 \pm 0.69$ & $6.68 \pm 1.06$ & $10.34 \pm 0.92$ & $16.56 \pm 0.51$ & $29.82 \pm 3.05$ \\
\hline $\mathrm{M} \pm \sigma[\min -\max ]$ & {$[2.35-4.20](n=10)$} & {$[4.47-8.13](n=10)$} & {$[8.08-11.27](n=10)$} & {$[15.76-17.18](n=10)$} & {$[26.82-33.34](n=6)$} \\
\hline Rate of healing, \% per day (Group 2), & $5.36 \pm 0.62 *$ & $11.65 \pm 0.98^{*}$ & $19.21 \pm 1.09 *$ & $23.27 \pm 2.28^{*}$ & $30.92 \pm 2.81$ \\
\hline $\mathrm{M} \pm \sigma[\min -\max ]$ & {$[4.24-6.32](n=10)$} & {$[10.27-12.99](n=10)$} & {$[16.87-20.56](n=10)$} & {$[19.92-25.00](n=4)$} & {$[28.12-33.33](n=2)$} \\
\hline $\begin{array}{l}\text { Completely healed wound, } \\
\% \text { of skin defect absence (Group } 1 \text { ) }\end{array}$ & 0 & 0 & 0 & 0 & $40(n=4)$ \\
\hline $\begin{array}{l}\text { Completely healed wound, } \\
\% \text { of skin defect absence (Group 2) }\end{array}$ & 0 & 0 & 0 & $60 * *(n=6)$ & $80 *(n=8)$ \\
\hline
\end{tabular}

* $-p<0.05$ as compared with Group 1.

Table 4. Dynamics of neutrophil and fibroblast count in wound surface biopsies

\begin{tabular}{|c|c|c|c|c|c|c|}
\hline \multirow[t]{2}{*}{ Index } & \multicolumn{6}{|c|}{ Day of wound treatment, $M \pm \Sigma$} \\
\hline & Start point $(0)$ & 3 & 5 & 7 & 11 & 14 \\
\hline$\%$ of neutrophils in the field of vision (Group 1 ) & $98.1 \pm 1.2$ & $95.9 \pm 2.1$ & $85.6 \pm 2.4$ & $73.2 \pm 2.7$ & $49.9 \pm 2.8$ & $38.7 \pm 1.3$ \\
\hline$\%$ of neutrophils in the field of vision (Group 2 ) & $97.9 \pm 1.8$ & $89.4 \pm 2.5^{*}$ & $72.6 \pm 2.9 *$ & $46.8 \pm 4.1^{*}$ & $36.0 \pm 1.5^{*}$ & $29.5 \pm 2.4^{*}$ \\
\hline$\%$ of fibroblasts in the field of vision (Group 1 ) & $1.4 \pm 1.1$ & $3.3 \pm 1.6$ & $6.2 \pm 1.5$ & $14.2 \pm 1.6$ & $32.9 \pm 1.8$ & $42.0 \pm 2.3$ \\
\hline$\%$ of fibroblasts in the field of vision (Group 2) & $1.5 \pm 0.9$ & $4.7 \pm 1.3 *$ & $11.6 \pm 2.2^{*}$ & $29.5 \pm 2.8^{*}$ & $41.7 \pm 2.3^{*}$ & $51.0 \pm 1.4 *$ \\
\hline
\end{tabular}

* - p $<0.05$ as compared with Group 1.

From day 7 the prevalence of fibroblasts and gradual decrease of neutrophils number was observed, and this reflects natural wound healing process. But in the wounds of animals from Group 2 the fibroblasts number was higher and neutrophils number was fewer. It also should be noted that the total cell count in the wound was reduced. Higher number of erythrocytes in the wound was found, which may be associated with microscopic injury to growing granulations during surface biopsy. It should be noted that while using the proposed method of hardwaresoftware wound treatment it was impossible to assess exudation because of dynamic wound irrigation.

\section{Discussion}

In general, a positive impact of the proposed hardwaresoftware method of treatment was noted on the healing process of infected wounds. This was observed as an accelerated wound healing and cleansing, and confirmed by a pronounced positive dynamics of the wound surface cells number and their ratio in Group 2. In Group 1 complications were observed during treatment of infected wounds: 1 case of continued purulence after wound closure and 2 cases of re-infection were registered. The causative agent of reinfection was Escherichia coli. It should be noted that there is an available meta-analysis of seventeen randomized controlled clinical trials reporting on 928 negativepressure wound therapy (NPWT) and 930 non-NPWT patients [35]. Surgical site infection was assessed, but there was no difference in terms of wound infection rate between NPWT and non-NPWT groups. It was noted that secondary complications, such as skin necrosis / blistering, dehiscence, reoperation, seroma / hematoma formation and bleeding, were less common in NPWT group compared with non-NPWT group. Our study, on the contrary, has revealed a faster decrease of wound size beginning from day 3 in animals from Group 2 versus Group 1.

Maximal reduction of wound area per day in Group 2 was observed 2-4 days earlier than in Group 1. Reaching this maximum marks, the transition of wound healing process to the second phase (granulation phase) and activation of regenerative mechanisms at the local level. It is known that hydromechanical debridement provides a potential mechanism for dislodging both devitalized tissue and its associated biofilm and the percussive forces delivered upon a wound surface by irrigation fluid stimulate granulation tissue formation and hasten wound closure. The similar results were obtained in the study based on evaluation of influence of computer-controlled wound irrigation with NPWT on bacterial load in contaminated wounds [36]. Also the number of different bacteria was analyzed during this study, which showed that automated instillation had a positive influence on reduction of bacterial load and optimized wound conditions before definite wound closure.

This all was achieved because the hardware-software method of infected wounds treatment described by us allows to automatically remove fragments of rejected necrotic tissue and sequesters directly from the wound surface and to ensure the absence of the porous constituents, which can be the basis for the 
formation of biofilm as an additional source of wound infection. In addition, this method allows dynamic monitoring of wound healing without total or partial interruption of hardware-software treatment due to transparency of airtight and water-resistant film placed over the wound (washing solutions are also transparent, so they do not interfere with wound inspection), which enables timely detection and prevention of complications and decisionmaking on necessity of wound suturing. Also this method enables to achieve effective concentration of medicines in the wound (as no absorbing porous composite components are needed), which increases the efficacy of treatment and reduces the cost of wound healing, and to use pharmaceutical solutions without wounds suturing. The use of hardware-software complex for treatment of superficial wounds is effective regardless of the degree of bacterial contamination and the phases of the wound healing process. This is consistent with the data presented in article [37] which contains discussion of the fact that mechanical debridement is the best way to remove biofilm as any residual pathogen can reconstitute the biofilm within days, because biofilm consists of complex microbial communities embedded in a protective extracellular polymeric substance. Moreover, efficacy of hydromechanical therapy offers a tremendous opportunity to reduce costs associated with treatment of chronic wounds.

\section{Conclusion}

The treatment of infected superficial wounds in liquid environment shortens the time of wound healing by $26.1 \%$. Use of proposed method leads to stimulation of reparative processes and rapid ceasing of inflammatory processes in infected wound. Application of treatment method that we used helps to prevent reinfection and suppuration. Treating these wounds in liquid environment makes the transition to second phase of wound healing process (proliferative phase) 1.7 times faster, which indicates higher efficacy of the proposed hardware-software method when compared with standard treatment under a dressing

\section{Limitations}

First of all, the aim of the present study could be wider because we evaluated only the efficacy of the developed method of infected superficial wound treatment in liquid environment, but we didn't present experimental data on evaluation of efficacy of the developed method for treatment of deep infected and contaminated wounds, which may be relevant for medicine.

Secondly, lack of previous studies in this area of research did not help authors to identify the scope of similar works that have been done so far, because the developed method has no analogs. Therefore, current research data in Scopus and Web of Science cannot be used to interpret our results.

\section{Conflict of Interest}

The authors declare that they have no conflict of interest.

\section{Ethical approval}

All procedures performed in studies involving animals were in accordance with the ethical standards of the institution or practice at which the studies were conducted. This study was approved by Kuban State Medical University Ethical Committee, registration number 45, 25.10.2016, Krasnodar, Russia.

\section{References}

1. Mokhova OS. Modern methods of treatment of purulent wounds. Journal of Anatomy and Histopathology 2013; 2(4): 2-15. Russian. https://elibrary.ru/item.asp?id=21274699.

2. Pilcher M. Wound cleansing: a key player in the implementation of the TIME paradigm. J Wound Care 2016; 25 (3 Suppl): S7-9. https://www.ncbi.nlm.nih.gov/pubmed/26949864.

3. Saidi R, Ghrab F, Kallel R, Feki AE, Boudawara $T$, Chesné $C$, et al. Tunisian clematis flammula essential oil enhances wound healing: GCMS analysis, biochemical and histological assessment. J Oleo Sci 2018; 67(11): 1483-1499. https://doi.org/10.5650/jos.ess18056.

4. Zhao $C$, Jin L, Tai S, Zhang X, Shi T, Wu F, et al. Purification of recombinant fusion polypeptide hEGF-AWRK6 and effect on wound healing and infection of burn model mice. Sheng Wu Gong Cheng Xue Bao 2018; 34(10): 1642-1649. Chinese. https://doi.org/10.13345/i.cib.180032.

5. West JM, Jordan SW, Mendel E, Khan SN, Chandawarkar RY, Valerio IL. Instillation negative pressure wound therapy: an effective tool for complex spine wounds. Adv Wound Care (New Rochelle) 2018; 7(10) 333-338. https://doi.org/10.1089/wound.2018.0793.

6. Krut UA, Shaposhnikov AA, Korokin MV. Research of wound healing effect of phytomineralsorbent on the basis of montmorillonite. Res Result Pharm and Clin Pharmacol 2017; 3(3): 9-19. https://elibrary.ru/item.asp?id=30101698.

7. Li X, Liu J, Liu Y, Hu X, Dong M, Wang H, et al. Negative pressure wound therapy accelerates rats diabetic wound by promoting agenesis. Int $J$ Clin Exp Med 2015; 8(3): 3506-3513. https://www.ncbi.nlm.nih.gov/pubmed/26064242.

8. Malmsjö $M$, Lindstedt $S$, Ingemansson $R$. Influence on pressure transduction when using different drainage techniques and wound fillers (foam and gauze) for negative pressure wound therapy. Int Wound J 2010; 7(5): 406-412. https://doi.org/10.1111/i.1742481X.2010.00706.x.

9. Xue SL, Yang J, Lü X. The evaluation of calcium alginate dressing helping wound healing of nail surgery. Sichuan Da Xue Xue Bao Yi Xue Ban 2018; 49(4): 652-655. Chinese. https://www.ncbi.nlm.nih.gov/pubmed/30378323.

10. Nolff MC, Albert R, Reese S, Meyer-Lindenberg A. Comparison of negative pressure wound therapy and silver-coated foam dressings in open wound treatment in dogs: a prospective controlled clinical trial. Vet Comp Orthop Traumatol 2018; 31(4): 229-238. https://doi.org/10.1055/s-0038-1639579.

11. Antoniadi YV, Volokitina EA, Chernitsyn DN, Pomogaeva EV, Gilev MV. Active surgical tactics at treatment of purulent-inflammatory complications osteosynthesis periarticular fractures. Voprosy Travmatologii $i$ Ortopedii 2012; 4(5): 25-29. Russian. https://elibrary.ru/item.asp?id=19093787.

12. Voyno-Yasenetsky VF. Purulent surgery essays. Moscow, Russia: Binom; Saint-Petersburg, Russia: Nevsky dialect, 2000. Russian. http://medotdel76.ru/uploads/files/voino_yaseneckiy_ocerki_gnoyno y hirurgii.pdf.

13. Giannini S, Mazzotti A, Luciani D, Lullini G, Tedesco G, Andreoli I, et al. Postoperative wound management with negative pressure wound therapy in knee and hip surgery: a randomised control trial. J Wound $\begin{array}{lll}\text { Care 2018; 27(8): 520-525. } & \end{array}$ https://doi.org/10.12968/jowc.2018.27.8.520.

14. Webster J, Scuffham P, Stankiewicz M, Chaboyer WP. Negative pressure wound therapy for skin grafts and surgical wounds healing by primary intention. Cochrane Database Syst Rev 2014; (10): CD009261. https://doi.org/10.1002/14651858.CD009261.pub3.

15. Mitish VA, Galstyan GR, Doronina LP, Tokmakova AYu, Kalmikov AV. Surgical treatment of Charcot foot with purulent infection. Diabetes Mellitus 2009; (1): 59-63. Russian. https://elibrary.ru/item.asp?id=13369575. 
16. Donlan RM. Biofilms: microbial life on surfaces. Emerg Infect Dis 2002; 8(9): 881-890. https://doi.org/10.3201/eid0809.020063.

17. Flemming HC, Wingender J. The biofilm matrix. Nat Rev Microbiol 2010; 8(9): 623-633. https://doi.org/10.1038/nrmicro2415.

18. Bazaliński D, Więch $P$, Kaczmarska D, Sałacińska I, Kózka M. Use of controlled negative pressure in management of phlegmon caused by fulminant complication of pressure wound: A case report. Medicine (Baltimore) 2018; 97(28): e11319. https://doi.org/10.1097/MD.0000000000011319.

19. Risman BV, Rybalchenko OV, Chmyrev IV. The role of ultrasound cavitation in the suppression of bacterial biofilms in patients with purulent-necrotic complications of diabetic foot syndrome. Vestnik Rossiiskoi Voenno-Medicinskoi Academii 2011; 2(34): 18-22. Russian. https://elibrary.ru/item.asp?id=16502397.

20. Percival SL, Thomas JG, Williams DW. Biofilms and bacterial imbalances in chronic wounds: anti-Koch. Int Wound J 2010; 7(3): 169175. https://doi.org/10.1111/j.1742-481X.2010.00668.x.

21. Westgate SJ, Percival SL, Knottenbelt DC, Clegg PD, Cochrane CA. Microbiology of equine wounds and evidence of bacterial biofilms. Vet Microbiol 2011; 150(1-2): 152-159. https://doi.org/10.1016/j.vetmic.2011.01.003.

22. Huang $C$, Leavitt $T$, Bayer LR, Orgill DP. Effect of negative pressure wound therapy on wound healing. Curr Probl Surg 2014; 51(7): 301331. https://doi.org/10.1067/j.cpsurg.2014.04.001.

23. Percival SL, Vuotto C, Donelli G, Lipsky BA. Biofilms and wounds: an identification algorithm and potential treatment options. Adv Wound Care (New Rochelle) 2015; 4(7): 389-397. https://doi.org/10.1089/wound.2014.0574.

24. Applewhite A, Chowdhry SA, Desvigne M, Gabriel A, Hill R, Obst MA, et al. Inpatient and outpatient wound treatment recommendations: assessing use of negative pressure wound therapy systems or oxidized regenerated cellulose (ORC)/ collagen/silver-ORC dressings. Wounds 2018; 30(8 suppl): S19-S35. https://www.ncbi.nlm.nih.gov/pubmed/30102238.

25. Fedosov PA, Nikolaevsky VA, Chernov YN, Buzlama AV, Slivkin Al, Provotorova SI. Preclinical study of the efficacy and safety of wound healing gel containing chitosan, taurine and allantoin. Res Result Pharm and Clin Pharmacol 2017; 3(2): 14-28. https://elibrary.ru/item.asp?id=29915008.

26. Lugauskas AYu, Mikulskiene Al, Laurene DY. Directory of micromycetes biodestruktorov polymeric materials. Moscow, USSR: Nauka, 1987; 341 p. Russian.

http://herba.msu.ru/shipunov/school/books/lugauskas1987 katalog mikr omitsetov-biodestruktorov.pdf.

27. Seth AK, Geringer MR, Gurjala AN, Hong SJ, Galiano RD, Leung KP, et al. Treatment of Pseudomonas aeruginosa biofilm-infected wounds with clinical wound care strategies: a quantitative study using an in vivo rabbit ear model. Plast Reconstr Surg 2012; 129(2): 262e-274e. https://doi.org/10.1097/PRS.0b013e31823aeb3b.

28. Pekhtasheva EL. Biodeterioration of non-food items. Moscow, Russia: Dashkov i K, 2013; 332 p. Russian. http://www.studentlibrary.ru/book/ISBN9785394017445.html.

29. Serkov A. Viscose fiber. Moscow, USSR: Chemistry, 1980; 296 p. Russian.

30. Guest JD, Moore SW, Aimetti AA, Kutikov AB, Santamaria AJ, Hofstetter $\mathrm{CP}$ et al. Internal decompression of the acutely contused spinal cord: Differential effects of irrigation only versus biodegradable scaffold implantation. Biomaterials 2018; 185: 284-300. https://doi.org/10.1016/j.biomaterials.2018.09.025

31. Rhoads DD, Wolcott RD, Percival SL. Biofilms in wounds: management strategies. J Wound Care 2008; 17(11): 502-508. https://doi.org/10.12968/jowc.2008.17.11.31479.

32. Bykov IM, Basov AA, Malyshko VV, Dzhimak SS, Fedosov SR, Moiseev AV. Dynamics of the pro-oxidant/antioxidant system parameters in wound discharge and plasma in experimental purulent wound during its technological liquid phase treatment. Bull Exp Biol Med 2017; 163(2): 268-271. https://doi.org/10.1007/s10517-017-3781-3.

33. Kovalenko IV, Kolesnichenko PD. Experimental rationale for the use of fluids with different redox potential as a basis for infusion therapy. Res Result Pharm and Clin Pharmacol 2017; 3(2): 29-37. https://elibrary.ru/item.asp?id=29915009.

34. Kamaev MF. Infected wound and its treatment. Moscow, USSR: Meditsina, 1970. 159 p. Russian.

35. Ge D. The safety of negative-pressure wound therapy on surgical wounds: an updated meta-analysis of 17 randomized controlled trials. Adv Skin Wound Care 2018; 31(9): 421-428. https://doi.org/10.1097/01.ASW.0000542530.71686.5c.

36. Ludolph I, Fried FW, Kneppe K, Arkudas A, Schmitz M, Horch RE. Negative pressure wound treatment with computer-controlled irrigation/instillation decreases bacterial load in contaminated wounds and facilitates wound closure. Int Wound J 2018; 15(6): 978-984. https://doi.org/10.1111/iwj.12958.

37. Desjardins H, Guo L. An overlooked but effective wound care methodology: hydromechanical therapy revisited. Plast Reconstr Surg Glob Open 2018; 6(8): e1883. https://doi.org/10.1097/GOX.0000000000001883.

\section{Authors:}

Aleksandr A. Basov - PhD, Full Professor, Department of Fundamental and Clinical Biochemistry, Kuban State Medical University, Krasnodar, Russia; Senior Researcher, Physics and Engineering Department, Kuban State University, Krasnodar, Russia. https://orcid.org/0000-0002-2262-4549.

Vadim V. Malyshko - Assistant, Department of General Surgery, Kuban State Medical University, Krasnodar, Russia; Researcher, Laboratory of Problems of Stable Isotope Spreading in Living Systems, Southern Scientific Centre of Russian Academy of Sciences, Rostov-on-Don, Russia. https://orcid.org/0000-0003-1323-0828.

Anna A. Elkina - Postgraduate, Department of Radiophysics and Nanotechnology, Kuban State University, Krasnodar, Russia; Junior Researcher, Laboratory of Problems of Stable Isotope Spreading in Living Systems, Southern Scientific Centre of Russian Academy of Sciences, Rostov-on-Don, Russia. https://orcid.org/0000-0002-9452-0132.

Arkadiy V. Moiseev - PhD, Researcher, Scientific Department, Kuban State Agrarian University, Krasnodar, Russia. https://orcid.org/0000-0001-7605$\underline{6826}$.

Stepan S. Dzhimak - PhD, Associate Professor, Physics and Engineering Department, Kuban State University, Krasnodar, Russia; Senior Researcher, Laboratory of Problems of Stable Isotope Spreading in Living Systems, Southern Scientific Centre of Russian Academy of Sciences, Rostov-on-Don, Russia. https://orcid.org/0000-0003-2618-5376. 